\title{
FAILURE ANALYSIS OF A FEMORAL HIP STEM MADE OF STAINLESS STEEL AFTER SHORT TIME OF EXPOSURE
}

\author{
Żaneta Anna MIERZEJEWSKA*, Zbigniew OKSIUTA*
}

\author{
${ }^{*}$ Faculty of Mechanical Engineering, Division of Materials and Biomedical Engineering, Bialystok University of Technology, \\ ul. Wiejska 45c, 15-351 Białystok, Poland \\ a.mierzejewska@doktoranci.pb.edu.pl, z.oksiuta@pb.edu.pl
}

\begin{abstract}
This paper describes a case study summarising the failure analysis of a stainless steel femoral stem, which failed prematurely within 36 months of exploitation in human body. In order to determine the mechanism of failure, a broken stem component were analyzed by means of macroscopic and microscopic obserwations and hardness measurements. Metallurgical obserwations revealed that the tested material does fulfill ASTM requirements. Scanning electron microscopy images revealed the presence of stress-induced cracking. The results of the hardness revealed significant nonuniformity from the surface towards the inner part of the stem. It is assumed that any discontinuity or defect on the fracture surface of the stem acted as preferential site for a crack nucleation and propagation by fatigue until the cross section of stem was not able to sustain a load generated by a patient.
\end{abstract}

Key words: Hip Replacement, Endoprosthesis Stem Fracture, Isolated Fracture, Total Hip Arthroplasty Complications, Fatigue Fracture

\section{INTRODUCTION}

Human locomotor system is composed of interrelated ligaments by means of joints and muscles, which are controlled by the nervous system (Dalaunay et al.,1996). A properly built and functioning hip joint allows for a smooth range of motion in multiple planes. Any disease in the joints may lead to their harm, causing its deformation, pain and loss of functionality. Total hip arthroplasty is one of the most successful practices in orthopedics, which restores the correct function of the hip joint disrupted by fracture or disease (rheumatoid arthritis, hip dysplasia, avascular necrosis of the femur) (Scheerlinck et al., 2004; Griza et al., 2013). This procedure intends to remove damaged articular joints and replace them with an artificial hip joint. During service life, artificial implants are exposed to an aggressive environment such as corrosion, wear and severe loading (Kamachi et al., 2003). These factors results in a wide range of failure mechanisms. One of the most serious complication is isolated stem fracture, consisting in breaking the implant inside the intramedullary canal, without damaging surrounding bone tissue. An incidence of this complication varies with many factors, including the patient population, for example the body mass index (BMI), physical activity, bone sideases or age and the geometry of the implant as well as kind of materials from which the artificial joint is made (Galante et al., 1980; Martens et al., 1974).

Biomaterials belong to the group of modern materials which are used for the replacement and reconstruction of human body. A very important group of biomaterials are metallic alloys, e.g.: stainless steels, Co-Cr alloys and $\mathrm{Ti}$ alloys. One of the common biomaterial used for bone implants and surgical instruments are austenitic stainless steels. Good mechanical properties, adequate biocompatibility and relatively low price of those alloys make them very suitable material for biomedical applications. The most popular stainless steels used for medical applications are 316L (ASTM A276-98b) and Rex 734 (ASTM F1586) grade.
An isulated failure of the femoral component after total hip arthroplasty is not a common occurrence from a statistical point of view, however there are some cases of stems fractures reported in the literature (Charnley, 1975; Mollan et al., 1985; Wilson et al., 1992; Malchau et al., 2002; Lakstein et al., 2011).

Roffey et al. (2012) described an isolated fatige fracture of the stem made of austenitic stainless steel after relatively short time of implantation $\sim 4.5$ years. The microstructure, hardness and chemical analysis of the fractured stem revealed good agreement with ISO standard requirements for such kind of implants. No defects such as cracks, non-metallic inclusions or corrosion were detected during observations of the fractured area. Also, the microstructure of the stem was homogeneous, with fine grains, typical for wrougth austenitic stainless steel. Detailed analysis of the fracture surface revealed two points of fracture initiation located on opposite sides of the stem. The location of these points, and the direction of the propagation of fatigue striations suggested that the stem fracture was caused by torsional loads.

Jarvi et al. (2007) also described an interesting case of a quadruple fracture of stem made of austenitic stainless steel, $316 \mathrm{~L}$ grade, after 4 years from imlpantation. Around the stainless steel stem granulation tissue was observed, which according to the authors knowladge could be due to wear products of acetabular cup. Striations on the fracture surfaces of the stem were observed as the result of a fatigue failure.

The most curious case of double isolated stem fracture, also made of austenitic stainless steel after 4.5 years of implantation, was described by Sen et al. (2009). On the basis of observations of the fracture area the authors proposed a hypothesis that the damage was caused by cyclic-variable load, leading to fatigue fracture.

Hernandez-Rodriguez et al. (2010) observed failure mechanism of the 316LV stainless steel stem where a main crack was originated on the anterolateral corner section of the material. Note that most of the cases reported in the literature concern the stem 
fracture made of 316 LV stainless steel grade, and there is no available information about fracture of the other kind of austenitic stanless steel, e.g. REX 734 .

The main goal of this work is to analyse and describe a failure mechanism of a hip stem made of austenitic stainless steel, REX 734 grade, after relatively short time of implantation, less than 3 years.

\section{EXPERIMENTAL PROCEDURE}

General image of the fractured stem is shown in Fig. 1. After revision, two parts of the fractured stems were prepared to further analysis. A small piece of material was cut from the stem and prepared for metallographic observations according to ASTM E130611 standard. The chemical composition of the stainless steel was examined by means of a spark emission spectroscopy (Thermo ARL Quantris, Switzerland). Microstructure observations after etching by means of the Vilella's echant (picric acid $1 \mathrm{~g} ; \mathrm{HCl} 5 \mathrm{ml}$; ethanol $100 \mathrm{ml}$ ) were carried out by an optical microscope (OM) a Nikon Eclipse LV1000. The fracture surfaces of stem were examined by means of Scanning Electron Microscopy (SEM) Hitachi S$3000 \mathrm{~N}$, equipped with Energy Dispersive Spectroscopy (EDS). Hardness measurements were performed using Vickers universal indenter with a load of $5 \mathrm{~kg}$. Grain size and hardness measurements were performed according to ASTM standards E112 and E384, accordingly.

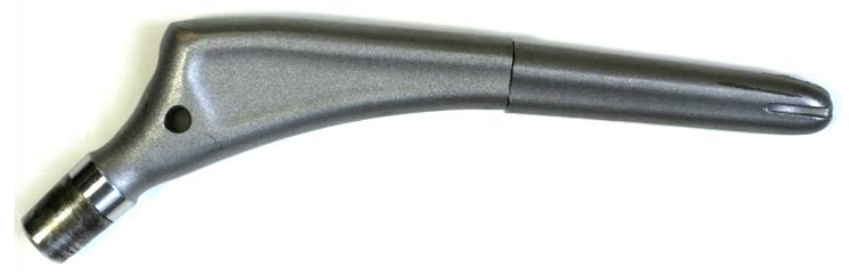

$150[\mathrm{~mm}]$

Fig. 1. General view of the fractured stainless steel stem

\section{RESULTS AND DISCUSSION}

The results of chemical analysis of the tested steel, presented in Tab. 1, revealed that the material of stem, in general, fulfils the requirements of ASTM F1586. However, there are some differences in chemical composition of the tested stem in comparison with the ASTM F1586 standard. Sulphur content is slightly higher than specified, whereas the nickel content is slightly reduced. Note that nitrogen, an element that stabilise a $\mathrm{Fe}-\gamma$ phase was not detected in the sample. It is well known that in austenitic stainless steels chrome and nickel concentration and their equivalent elements content play very important role for stabilisation of the FCC phase structure. Chromium and nickel equivalents can be calculated according to Equations (1) and (2).

$$
\begin{aligned}
& \mathrm{R}_{\mathrm{Cr}}=(\% \mathrm{Cr})+(\% \mathrm{Mo})+1.5(\% \mathrm{Si})+0.5(\% \mathrm{Nb})+2(\% \mathrm{Ti}) \\
& \mathrm{R}_{\mathrm{Ni}}=(\% \mathrm{Ni})+30(\% \mathrm{C}+\% \mathrm{~N})+0.5(\% \mathrm{Mn})
\end{aligned}
$$

Calculated $\mathrm{Cr}$ - and $\mathrm{Ni}$ - equivalents exhibited $12.80 \%$ and $22.75 \%$, respectively. Therefore, fully austenitic structure is expected. This was confirmed by the XRD measurements of the tested stem (not presented here).

Tab. 1. Chemical composition of the stems and ASTM F1586 standard (\% weight)

\begin{tabular}{|c|c|c|c|c|c|c|}
\cline { 2 - 6 } \multicolumn{1}{c|}{} & $\mathbf{C}$ & $\mathbf{S i}$ & $\mathbf{M n}$ & $\mathbf{P}$ & $\mathbf{S}$ & $\mathbf{N b}$ \\
\hline $\begin{array}{c}\text { ASTM F } \\
\mathbf{1 5 8 6}\end{array}$ & $0.08^{\mathrm{a}}$ & 0.75 & $2-4.25$ & $0.025^{\mathrm{a}}$ & $0.01^{\mathrm{a}}$ & $\begin{array}{c}0.25- \\
0.8\end{array}$ \\
\hline Sample & 0.036 & 0.27 & 4.1 & 0.002 & 0.015 & 0.39 \\
\hline $\begin{array}{c}\text { ASTM F } \\
\text { 1586 }\end{array}$ & $\begin{array}{c}19.5- \\
22\end{array}$ & $2-3$ & $0.25^{\mathrm{a}}$ & $9-11$ & $\begin{array}{c}0.25- \\
0.5\end{array}$ & \multicolumn{1}{c}{} \\
\cline { 1 - 6 } Sample & 21.14 & 2.33 & 0.036 & 7.05 & - \\
\cline { 1 - 6 }
\end{tabular}

(a - maximum content)

SEM-EDS linear analysis was also performed to observe changes in the concentrations of main alloying elements along a cross-section of the stem as it is presented in Fig. $2 a$. The results presented in Fig. $2 b$ confirmed a homogeneous distribution of alloying elements in the steel matrix.

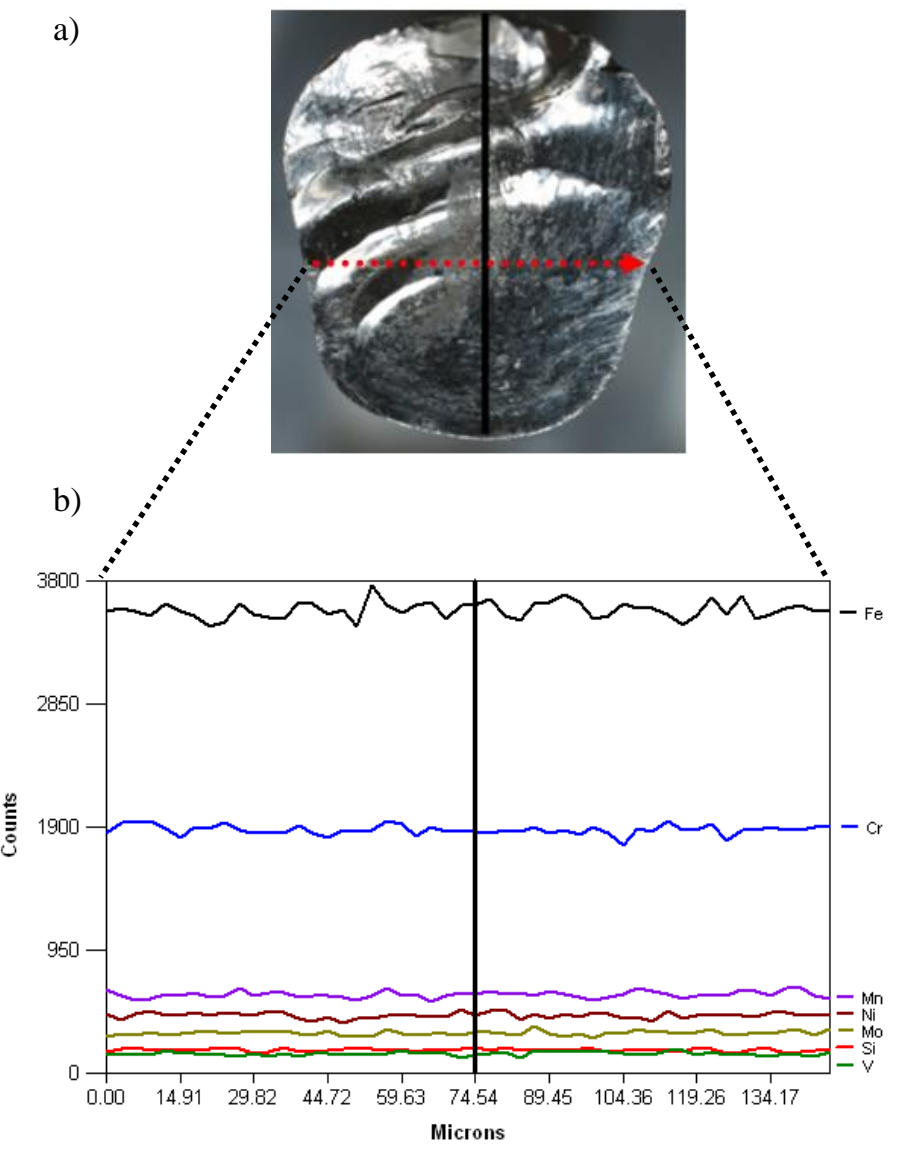

Fig. 2. SEM-EDS linear analysis of the elements concentration on the surface of the stem - (a) macroscopic view (b) - elements distribution

OM image of the etched microstructure of the tested sample, presented in Fig. 3 showed equiaxed austenitic grains and twins characteristic for forged and annealed austenitic stainless steels. Note, that no delta ferrite was observed. 
In general, the microstructure is quite homogeneous, with an average grain size of $36 \pm 3 \mu \mathrm{m}$ (no 7 according to ASTM). However, larger grains near the surface of the stem were also observed which may cause an origin of a fatigue crack initiation of the steel (Fig. 3b). This inhomogeneity of the grain size is difficult to explain, however, this may be related to hardness results presented in the section 3.3 (Fig. 6).
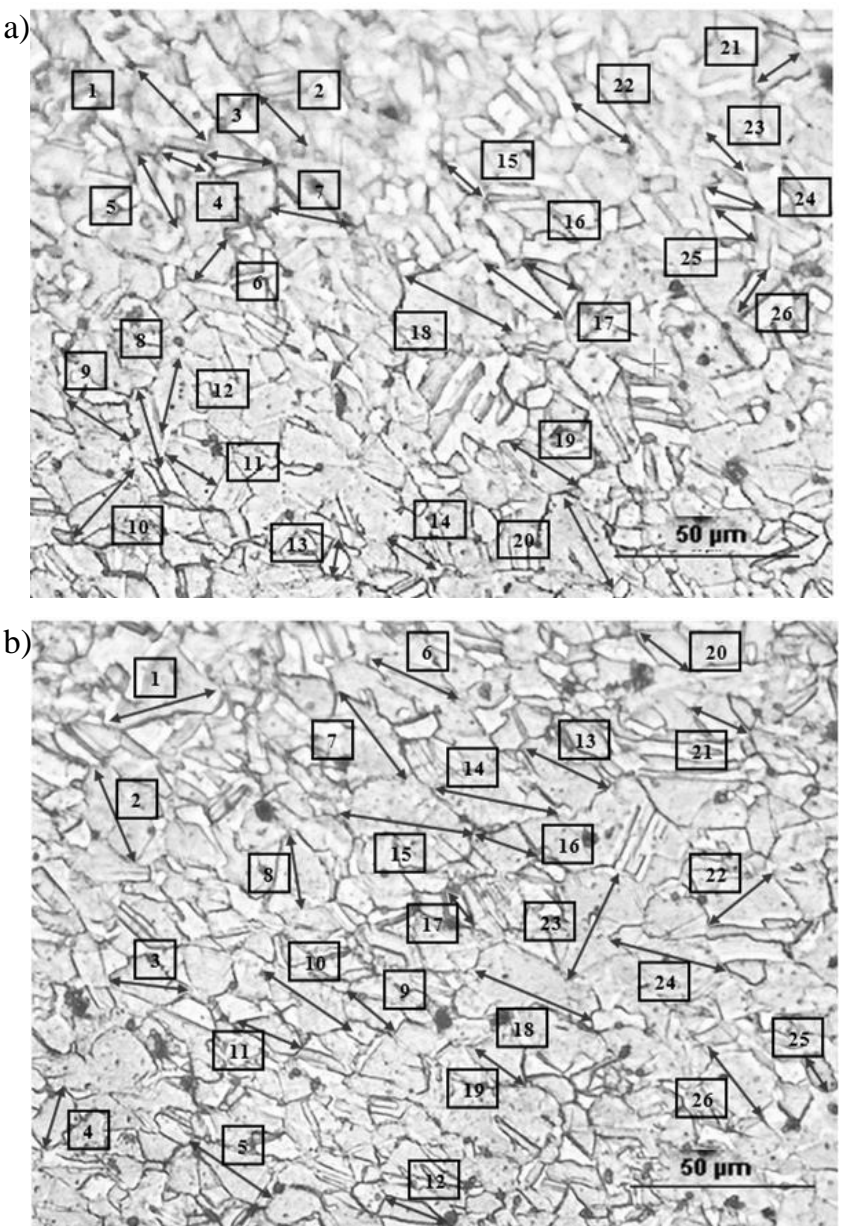

Fig. 3. Typical OM microstructure of the femoral stem;

(a) taken from inside of the stem
(b) taken from an edge of the stem

Fig. 4 shows a general view of the fractured surface of the tested material. The image shows a several distinctive features typical for fatigue fracture: an origin where a crack can be initiated (zone a), fatigue striations (zone b), and a final fracture area (zone $\mathrm{c}$ ). The fatigue fracture probably was initiated close to the lateral edge of the material, and further propagated until a cross section of the stem was no longer strong enough to bearing the applied load and it finally broke. The fatigue zone is unique to fatigue fractures because it is the region where the crack grows from the origin to the final fracture zone. It should be pointed out that the geometry of the fractured stem did not reveal any changes. No bending of stems was observed. Also, no traces of corrosion were discovered.

Fig. 5 shows SEM images of the fractured surface. Fig. 5a presents the magnified cracks initiation region whereas Fig. $5 b$ shows some of the "beach marks" (progression lines) area. Each mark or line was created when the crack stops after short distance propagation. These patterns are not clearly visible, probably because the fracture surfaces were severally smashed, as a result of friction of both broken parts during prolonged walking after fracture. There is another possible explanation reported by Brown (2014) and related to very fine microstructure of steel or unchanged load during fatigue damage.

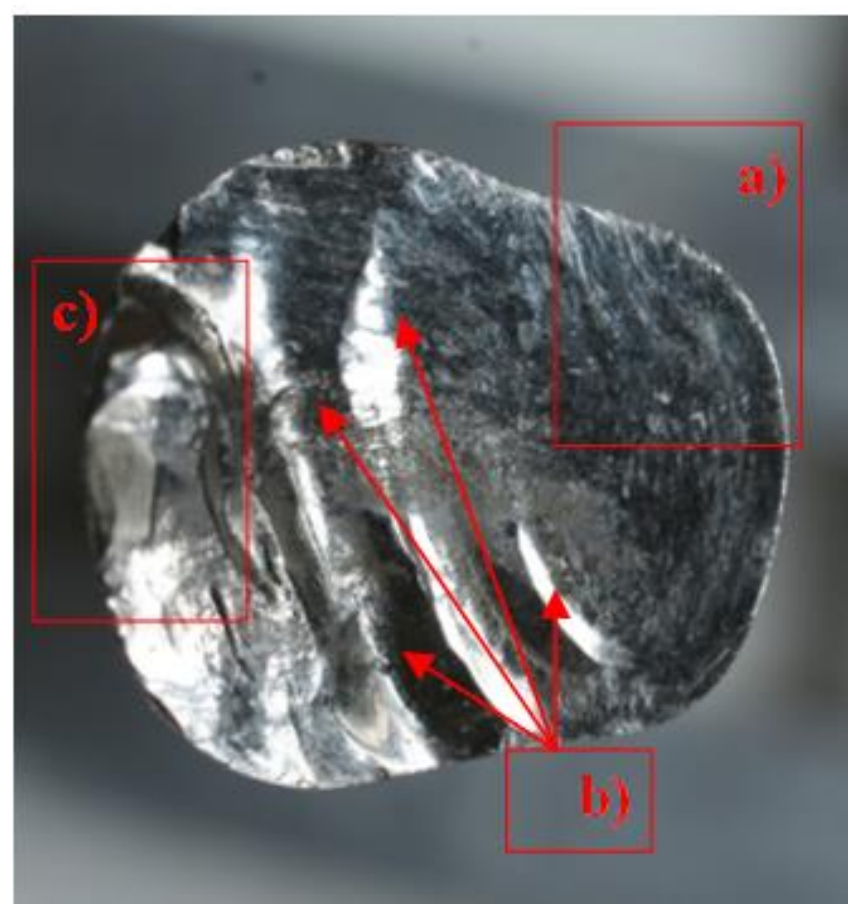

Fig. 4. Fatigue surface with fracture view showing the zones:

a) an origin, b) progression lines

c) and a final fracture zone

As the cracked stem continues to be stressed, the crack progresses across the section. The amount of material carrying the load is decreasing, so the stress is obviously increasing. Fig. $5 \mathrm{c}$ confirms extensive friction islands at the fracture surface, however higher magnification image in Fig. $5 d$ shows typical fatigue striations. In Fig. 5e numbers of secondary cracks were observed, propagated perpendicular to the loading direction. The length of these cracks corresponds well to the grain size of the steel. This type of fracture may be caused by the presence of non metallic inclusions. Fig. $5 f$ shows the SEM image of the final fracture stage, where the unbroken area is reduced to the point that the applied stress exceeds the ultimate strength of the material.

The origin of fatigue fracture commonly takes place in the anterolateral site of the hip stem due to the highest stresses created under in-service conditions.

The hardness measurements of both parts of the broken stem was performed few milimeters below and above of the fracture. An average hardness of tested material is $\sim 335 \mathrm{HV} / 5$ and fulfils ASTM requirements. However, an interesting effect was observed, not equal and strong dependence of hardness of the measurement site. In the middle of the cross section of the stem the hardness is $360 \pm 2 \mathrm{HV} / 5$ and close to the edge of the cross section of the specimen is about $10 \%$ lower, $325 \pm 5 \mathrm{HV} / 5$ (see Fig. 6). 
a)

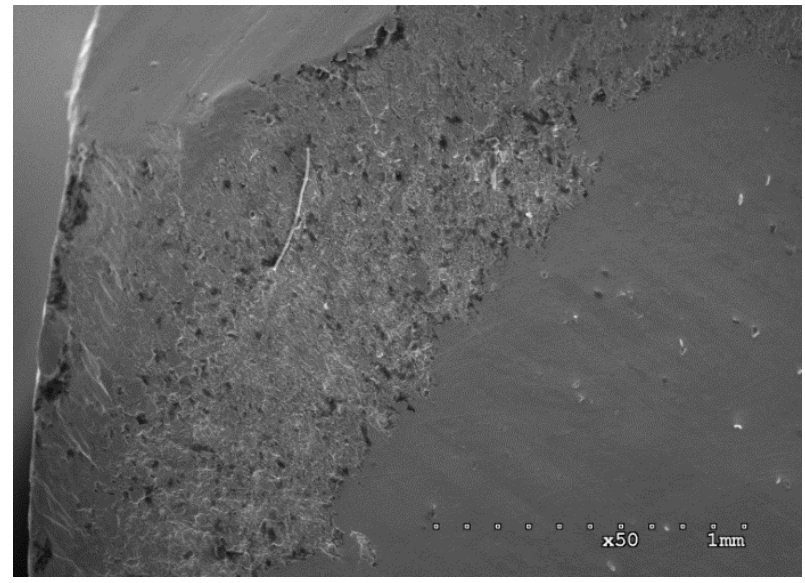

c)

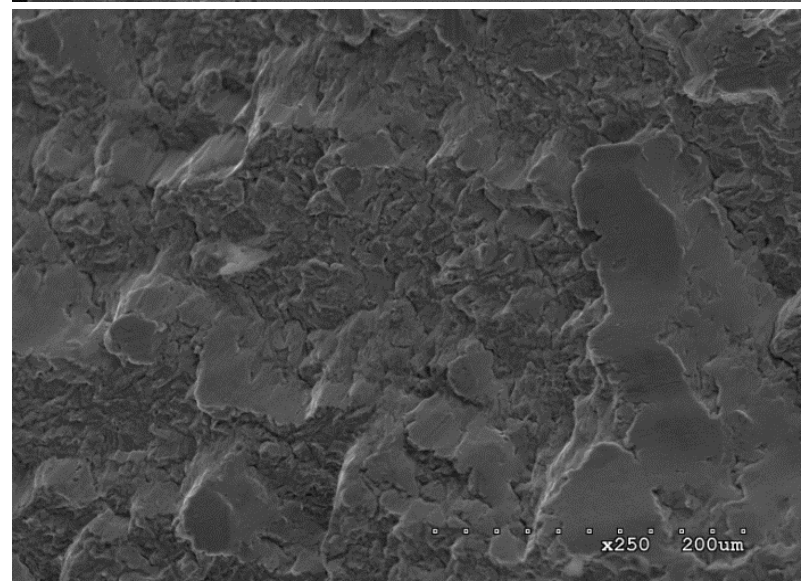

e)

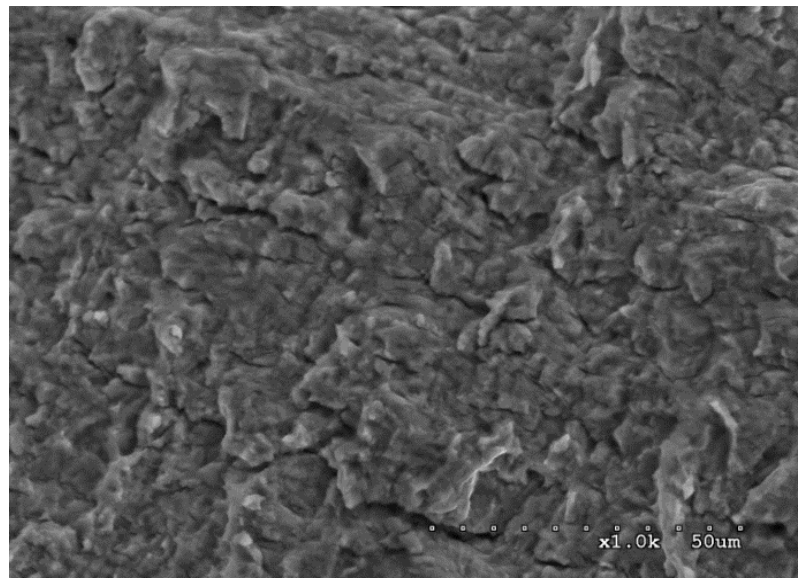

b)

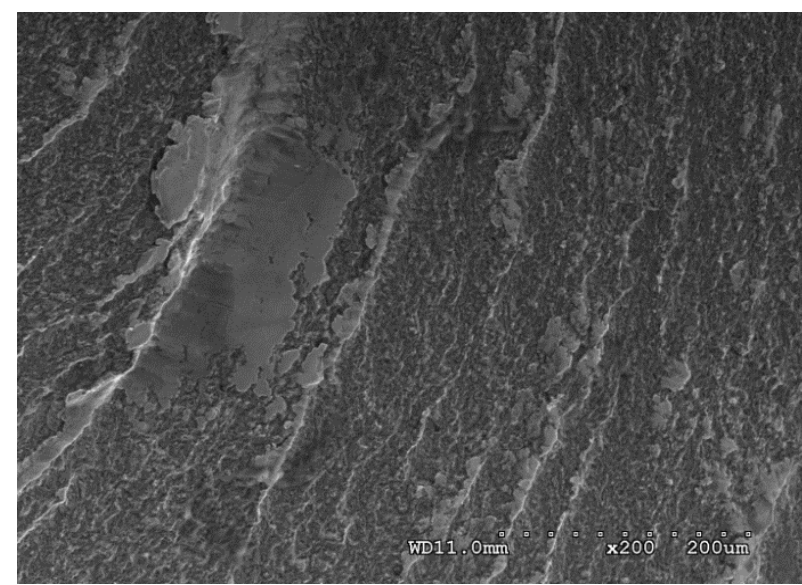

d)

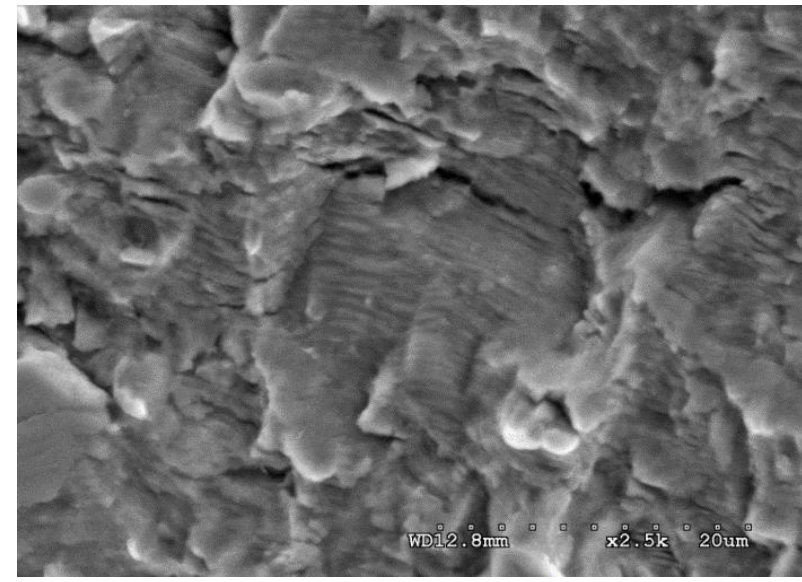

f)

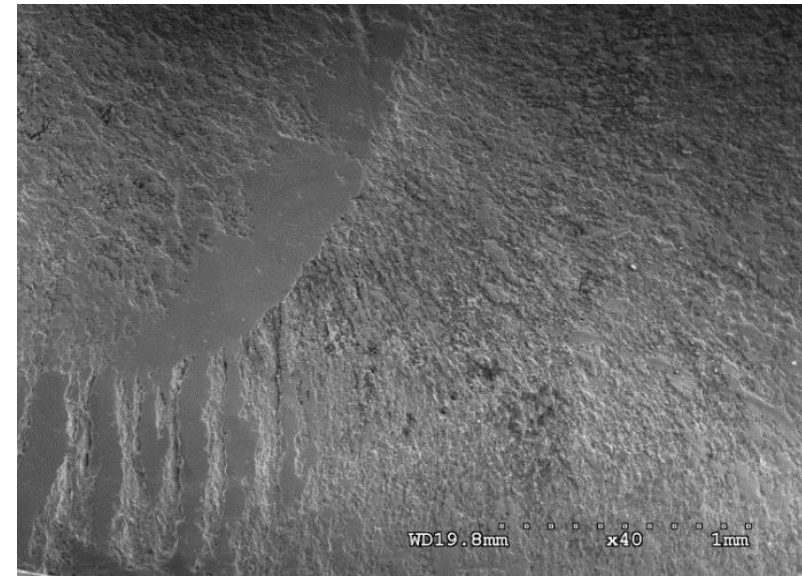

Fig. 5. SEM images of the fracture surfaces of the tested steel failed by fatigue fracture demonstrating: (a) origin of the failure (b) beach marks area;

(c) wear islands on the fracture surface ; (d) fatigue striation; (e) secondary cracks and fatigue tears; (f) final fracture area

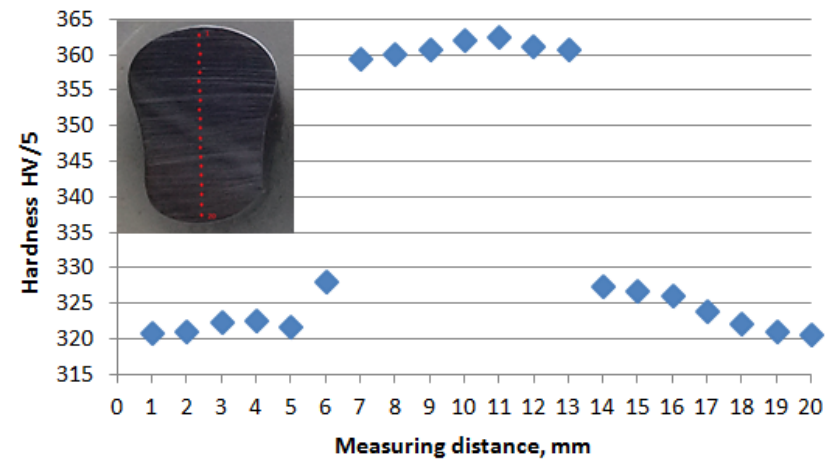

Fig. 6. Hardness measurements of the tested stem as a function of the distance from the edge of the sample
It is not a significant scutter of the hardness of the tested specimen, however it is difficult to explani, because these results are not consistent with the microstructure observations presented in Fig. 3. According to the Hall-Petch equation (Petch, 1953) with decreasing the grain size the ductility and hardness of the material increase. On the other hand this statemant is not valid for some groups of materials, especially with subgrain microstructure.

Stem fracture in the femoral component of total hip arthroplasty may have a complex etiology. The most important factors that cause fracture of metallic stem should be mentioned: the hidden material defects, incorrectly realized thermo-mechanical and /or heat treatment, improper design of the implant (incorrectly matched to the load), improper fixing in the bone or inapropriate exploitation (Galante et al., 1980; Kishida et al., 2012). The fracture of femoral 
stem may be also caused by one factor or the combination of factors including: high stress applied in the stem due to high level of activity or fast patient weight gain, undersized prosthesis, poor proximal bone support or fixation, varus orientation of the stem and material defects.

Series of tests conducted in this work revealed that the REX 734 stainles steel in general fulfills ASTM F1586 standard requirements. The microstructure of the stem is homogeneous and possesses relatively small grains. There are no changes caused by intergranular or pitting corrosion, since homogeneous distribution of main alloying elements, especially chromium, were detected.

On the contrary the results of the hardness revealed measurable inhomogeneity coming from the edge towards innert part of the material. This is difficult to explain and more tests have to be conducted.

Macroscopic fatigue striations, commonly known as beach marks, were visible. The beach marks were closely spaced indicating a large number of cycles to failure, which eliminates the possibility of sudden overload failure. Final failure occurred on the lateral side corner. SEM examination of the fractured surface revealed secondary cracks, which are the result of tensile and compressive stresses induced in the material during patient's walking.

\section{CONCLUSION}

The main goal of this work was to analyse and describe a failure mechanism of cemented hip stem made of austenitic stainless steel, REX 734 grade. The tested material, in general, fulfils ISO 5832-1 standard, however, there are some factors such as: lower $\mathrm{Ni}$ and $\mathrm{N}$ content, inhomogenous grain size, higher hardness measured in the inner part of the stem and secoundary cracks initiated at the non-metalic inclusions, that can explain early fracture of the hip endoprosthesis after 3 years of implantation.

\section{REFERENCES}

1. Brown T. (2012) Preventing Mechanical Failures - An Introduction to Failure Mode Identification, A Culture of Reliability, Vol. 3, 46-48.

2. Charnley J. (1975), Fracture of femoral prostheses in total hip replacement : a clinical study. Clin Orthop, $111: 105-20$.

3. Delaunay, C. P., Kapandji, A. I. (1996), Primary total hip arthroplasty with the Karl Zweymuller first-generation cementless prosthesis: a 5 to 9 year retrospective study, J. Arthroplasty, 11, 643.652.

4. Galante J. (1980), Current Concept Review Causes of Fractures of the Femoral Component in Total Hip Replacement, Journal of Bone and Joint Surgery, Vol. 62 (4), Vol. 62(4), 670-673.

5. Griza S., Vieira dos Santos S., Ueki M. M., Bertoni F., Strohaecker T.R. (2013), Case study and analysis of a fatigue failure in a THA stem, Engineering Failure Analysis, 28, 166-175.

6. Hernandez-Rodriguez M. A. L., Ortega-Saenz J. A., Cotreras-Hernandez G. R. (2010), Failure analysis of a total hip prosthesis implanted in active patient, Journal of the Mechanical Behavior of Biomedical Materials, Vol. 3 (8), 619-622.

7. Jarvi K., Kerry R. M. (2007), Case Report Segmental Stem Fracture of a Cemented Femoral Prosthesis, The Journal of Arthroplasty, Vol. 22(4), 612-616.

8. Kamachi M. U., Sridhar T. M., Eliaz N., Baldev R. A. J. (2003), Failures of stainless steel orthopaedic devices: causes and remedies, Corros Rev, 21, 231-67.

9. Kishida Y.,Sugano N., Ohzono K., Sakai T., Nishii T., Yoshikawa H. (2002), Stem Fracture of the Cementless Spongy Metal Lu" beck Hip Prosthesis, The Journal of Arthroplasty, Vol. 17 (8), 1021-1027.

10. Lakstein D., Eliaz N., Levi O, Backstein D., Kosashvili Y., Safir O., Gross A. E. (2011), Fracture of Cementless Femoral Stems at the Mid-Stem Junction, J Bone Joint Surg Am., 93, 57-65.

11. Malchau H, Herberts P, Eisler T, Garellick G, Soderman P. (2002), The Swedish Total Hip Replacement Register, J Bone Joint Surg Am, 84-A, Suppl 2, 2-20.

12. Martens M., Aernoudt E., De Meester P., Ducheyne P., Muller J. C., Delangh R., Kestelijn P. (1974), Factors in the Mechanical Failure of the Femoral Component in Total Hip Prosthesis, Acta Orthop Scandinavica, 45(5), 693-710.

13. Mollan R. A. B., Watters P. H., Steele R., McClelland C. J. (1984), Failure of the femoral component in the Howse total hip arthroplasty, C/in Orthop, 190, 142-7.

14. Petch N. J. (1953), The cleavadge strength of policrystalls, JISi, 174, 25-28.

15. Roffey P. (2012), Case study: Failure of a high nitrogen stainless steel femoral stem, Engineering Failure Analysis, Vol. 20, 173-182.

16. Scheerlinck T, Druyts P, Casteleyn P. (2004), The use of primary total hip arthroplasty in university hospitals of the European Union, Acta Orthop Belg, 70(3), 231-9.

17. Sen R. K., Mootha A. K., Saini R., Kumar V. (2009) Segmental Fracture Of A Cemented Femoral Stem - A Case Report And Review Of Litrature, The Internet Journal of Orthopedic Surgery, Vol. 13 (1), 13-15.

18. Standard Specification for Wrought Nitrogen Strengthened 21 Chromium-10 Nickel-3 Manganese-2.5 Molybdenum Stainless Steel Alloy Bar for Surgical Implants, American Society for Testing and Materials, Materals, West Conshohocken, PA, ASTM F1586.

19. Wilson L. F., Nolan J. F., Wood-Waddington M. B. (1992), Fracture of the femoral stem of the ring TCH hip prosthesis, J Bone Joint Surg $\mathrm{Br}, 74(5), 725-8$.
Acknowledgements: This scientific work was supported by the Faculty of Mechanical Engineering, Bialystok University of Technology, project No MB/WM/14/2014. 